RESEARCH REPORT

\title{
Employee control over working times: associations with subjective health and sickness absences
}

\author{
L Ala-Mursula, J Vahtera, M Kivimäki, M V Kevin, J Pentti
}

J Epidemiol Community Health 2002;56:272-278

See end of article for authors' affiliations

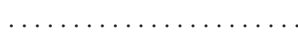

Correspondence to: Dr L Ala-Mursula,

Development and Service

Centre of Occupational

Health, City of Oulu,

Mäkelininkatu 31

FIN-90100 OULU, Finland;

Leena.Ala-Mursula@oulu.fi

Accepted for publication 24 July 2001

\begin{abstract}
Study objective: To investigate the impact of employees' worktime control on health, taking into account other aspects of job control.

Design: Analysis of questionnaire data in 1997 and register data on sickness absence during 19961998.

Setting: Eight towns in Finland.

Participants: 6442 municipal employees (1490 men and 4952 women) representing the staff of the towns studied. Follow up was 17706 person years.

Main results: In women, poor health and psychological distress were more prevalent among those in the lowest quartile of worktime control than those in the highest (after adjustment for potential confounders including other aspects of job control, odds ratios and their $95 \%$ confidence intervals for poor health and psychological distress were 1.8 (1.5 to 2.3) and 1.6 (1.3 to 2.0), respectively). Correspondingly, the adjusted sickness absence rate was $1.2(1.1$ to 1.2$)$ times higher in women with low worktime control than in women with high worktime control. In men, no significant associations between worktime control and health were found. These results, obtained from the total sample, were replicable within a homogeneous occupational group comprising women and men.

Conclusions: Exploration of specific aspects of job control provides new information about potentially reversible causes of health problems in a working population. Worktime control is an independent predictor of health in women but not in men. Dissimilarities in the distribution of occupations between men and women are not a probable explanation for this difference.
\end{abstract}

S everal studies have demonstrated the association between job control and various aspects of health, for example, cardiovascular morbidity and mortality, ${ }^{1-6}$ sickness absence, ${ }^{7-10}$ and subjective health. ${ }^{11-14}$ Although this general association is well established, an extension of research to the health effects of the various dimensions of job control has been called for. ${ }^{15-17}$ To date, there is evidence relating to aspects such as skill discretion, ${ }^{78-21}$ decision authority, ${ }^{70-22}$ control over work pace, ${ }^{1823}$ participation in decision making ${ }^{202124}$ and predictability (control over potential uncertainty). ${ }^{21}$ However, considerably less is known about the impact of employees' worktime control on health. This is surprising, as timing of activities may be one of the mechanisms underlying the health effects of job control. A high level of control over working times provides opportunities to adjust job demands with the prevailing state of resources. Worktime control may also help in integrating working life with private life.

Indirect evidence suggests that worktime control may indeed play a part in employee health. Health problems have been shown to be associated with machine paced work, ${ }^{18} 25$ which is characterised by poor worker control over scheduling and duration of breaks within a workday. In addition, a recent meta-analysis suggests that flextime scheduling, providing employees with control over the starting and ending times of a workday, is associated with lower absenteeism. ${ }^{26}$ Poor worktime control at occupational level has been associated with an excess of hospitalisations and cardiovascular morbidity. ${ }^{27} 28$ However, evidence of an association between employee control over working times and health, across various health outcomes, is still lacking.

The aim of this study was to determine the association between worktime control and health. The former was operationalised as perceived control over starting and ending times of a workday, the opportunities to take breaks and to deal with private matters during the workday, the scope for influencing the scheduling of shifts, the scheduling of paid days off and vacations, and the opportunities to take unpaid leave. Health was measured through three different outcomes: subjective ratings of general health, psychological distress, and register based sickness absences.

\section{METHOD}

\section{Participants and design}

Data were drawn from the ongoing 10-Town study, a Finnish cohort study exploring the relations between psychosocial and behavioural factors and health. In November 1997, a total of 1490 male and 4952 female identifiable full time permanent municipal workers representing the personnel of the eight towns agreed to participate in the study, and responded to a questionnaire designed to allow for the assessment of worktime control, job control, job demands, health risk behaviour, and health. Of the respondents $23 \%$ were men and $77 \%$ women. The mean age of men was 46.1 (SD 8.5) years and that of women 44.8 (8.5) years. The response rate was $67 \%$. The true response rate is likely to be higher, however, because $6 \%$ of the employees on the lists provided by the employers had moved before the study and were therefore not eligible for inclusion. The employers' records from 1 January 1996 to 31 December 1998 relating to medically certified (over three days) sickness absences and the follow up times of these employees were analysed as in our earlier studies. ${ }^{20} 29$ The follow up time was 4171 years for men and 13535 years for women. The rate of medically certified sickness absence per 100 person years in 1997-98 was 61.4 in men and 80.2 in women.

In the eligible population (that is, all the 24351 permanent full time employees of the eight towns in 1997), $28 \%$ were men and $72 \%$ women. The mean age of men was 45.3 (SD 8.7) years and that of women 45.0 (SD 8.5) years. The rates of 
medically certified sick leave per 100 person years in 1997-98 were 68.9 in men and 87.3 in women.

The sample represented the eligible population well. In terms of age, practically no differences were evident. The proportion of women and the rate of medically certified sickness absence were somewhat higher in the sample than in the eligible population.

The study was approved by the ethics committee of the Finnish Institute of Occupational Health.

\section{Worktime control}

Worktime control was measured on a six item scale, modified from a standard survey instrument of Statistics Finland.$^{30}$ The respondents were asked to rate how much they were able to influence the following aspects of their working times:

(1) the starting and ending times of a workday

(2) the taking of breaks during the workday

(3) handling private matters during the workday

(4) the scheduling of workshifts

(5) the scheduling of vacations and paid days off, and

(6) the taking of unpaid leave.

The items cover most of the worktime control processes contained in the regulations concerning work contracts. Our scale also operationalises a key element of the different worktime models applied in modern working life-that is, autonomy with regard to worktime (worker control over the duration, position, and distribution of his/her individual worktime). ${ }^{31}$ Finally, the scale covers topics that are regarded as important in research into job control, but which have been neglected. ${ }^{32}$ These include (a) control over work scheduling, for example, working hours (item 1), vacations and days off (items 5 and 6) and choice of shifts (item 4), as well as (b) control over work pacing, for example, scheduling and duration of rest breaks (items 2 and 3).

Responses were given on a five point scale $(\mathrm{l}=$ very little, $\ldots$, $5=$ very much). We used the mean of the six items (Cronbach's $\alpha 0.82$, mean 2.78 and SD 0.87).

\section{Health}

Self rated health was assessed by an overall rating of health on a five point scale $(1=$ good, $2=$ fairly good, $3=$ average, $4=$ fairly poor, $5=$ poor ). This measure was dichotomised by grouping response scores 1-2 as a category of good health and scores $3-5$ as a category of poor health. Self rated health is a widely used concept in medical, epidemiological, and health psychological research. It has been a powerful predictor of mortality and morbidity ${ }^{33}{ }^{34}$ and has been shown to be associated with the number of physician contacts per year in a working population..$^{35}$ In our sample 507 men (34.3\%) and 1549 women $(31.6 \%)$ had poor health.

Psychological distress was obtained from the 12 item version of Goldberg's (1972) General Health Questionnaire (GHQ-12), which has been developed to serve as a screen for unspecific psychiatric morbidity in populations. ${ }^{36}$ In the 12 items respondents consider symptoms of psychiatric morbidity, for example, feelings of depression, loss of confidence or sleep disturbances. As in studies validating the GHQ-12 against standardised psychiatric interviews, we used the cut off point of experiencing at least four of the symptoms more than usual to indicate psychological distress. ${ }^{37}$ In this sample 345 (23.2\%) men and 1242 (25.2\%) women had psychological distress.

Sickness absence data, drawn from the employers' records, covered the period from l January 1996 to 31 December 1998. Sick leave periods in 1996 (yes/no) were treated as baseline absenteeism and the total of sick leave periods in 1997-98 as an outcome measure. Records were checked for inconsistencies. Overlapping and consecutive spells of sickness absence were combined. Employers participating in the 8-Town Study routinely record each sick leave period for every employee, including the dates when each spell started and ended. In accordance with regulations, each sick leave certificate must be forwarded for recording. In the towns studied, employees are paid a full salary during their sick leave from the first day. Municipal employers receive compensation for salary losses attributable to sick leave longer than 10 days from the Finnish Social Insurance Institution. To receive all the compensation to which they are entitled, employers keep strict records of all sick leave. The employees can complete their own certificates for sick leave of up to three days. Focusing on health, we used as an outcome only sick leaves longer than three days, for which medical certificates are always required.

Maternity leave and absence from work to care for a sick child are not included in the sickness absences. The regulations concerning work contracts offered by Finnish municipalities permit employees to be absent from work, without loss of salary, to care for children under 10 years of age suffering from an acute illness. Each such absence is fully reimbursed for up to three days, and there are no limitations on the number of such absences per employee per year. Thus, the participants had no reason to claim they were ill when they were in fact looking after a sick child.

\section{Other predictors of health}

Job control was measured on nine item decision latitude scale from Karasek's Job Content Questionnaire. ${ }^{38}$ This scale is a widely used measure of job control and assesses two aspects of control: skill discretion and decision authority. The measure was a simple sum of eight of the nine items (we excluded the item "My job involves a lot of repetitive work" because it substantially reduced the internal consistency of the scale). The Cronbach $\alpha$ of the scale was 0.82 , range $1-5$, mean 3.82 and SD 0.62 .

Job demands scale, which assesses workload, work pace and conflicting demands, was also derived from Karasek. ${ }^{38}$ The measure was a simple sum of ten items, Cronbach's $\alpha$ was 0.81 , range $1-5$, mean 3.27 and SD 0.65 .

Other predictors of health included demographic factors (gender, age, socioeconomic status, and family characteristics) and health risk behaviour. Socioeconomic status was measured in terms of the respondent's education: no vocational education (23\% of men, $23 \%$ of women), vocational education ( $23 \%$ of men, $22 \%$ of women), college ( $26 \%$ of men, $33 \%$ of women) and university education ( $29 \%$ of men, $22 \%$ of women). Measurement of occupational status was based on ISCO-88 COM, the international standard classification of occupations. ${ }^{39}$ Under this classification, respondents' occupations ( 979 job titles in employers' records) were categorised as managers and professionals ( $41 \%$ of men, $38 \%$ of women), associate professionals and clerks (17\% of men, $34 \%$ of women), and manual workers ( $42 \%$ of men, $28 \%$ of women). Of the family characteristics we recorded marital status $(79 \%$ married or cohabiting, $21 \%$ single, divorced or widowed) and children living at home (yes $60 \%$, no $40 \%$ ). In terms of smoking, the respondents were grouped into never smokers, ex-smokers and current smokers $(43 \%, 39 \%$ and $18 \%$, respectively). Alcohol consumption was measured as in Kaprio et $a l^{40}$ and dichotomised into high consumption (more than $210 \mathrm{~g}$ of alcohol a week, $9.0 \%$ of participants) versus low or no consumption. ${ }^{41}$ Weight and height were recorded to measure body mass index (mean 25.2 and SD $4.1 \mathrm{~kg} / \mathrm{m}^{2}$ ). Sedentary lifestyle was indicated by leisure time physical activity corresponding to under half an hour of fast walking per week $(15.4 \%){ }^{42}$

\section{Statistical analyses}

We used analyses of variance to study the associations between worktime control and other predictors of health. To study the relations between other predictors and health, regression analyses were applied. Logistic regression was used 


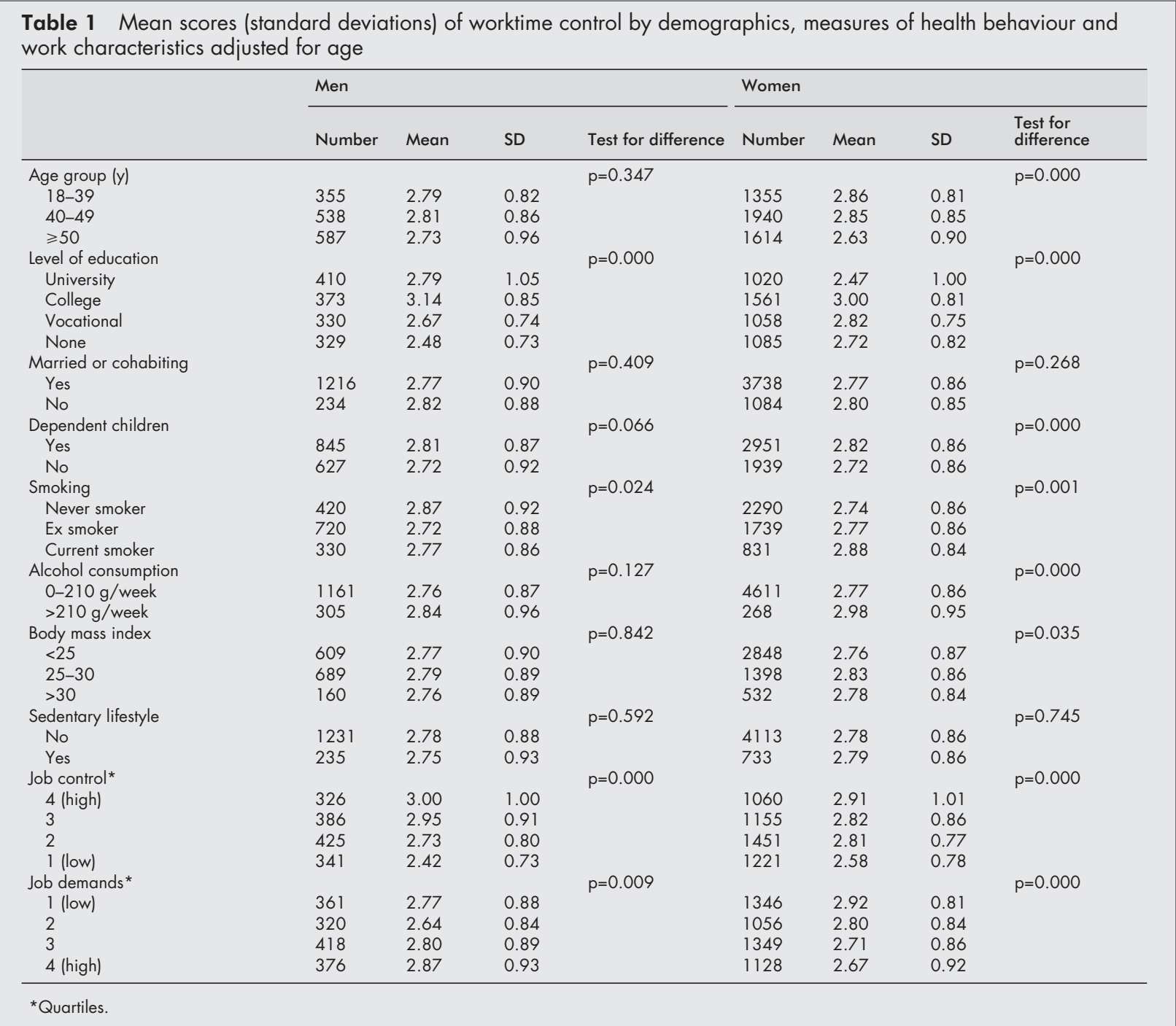

in relation to self rated health and psychological distress and Poisson regression models in relation to sickness absence. ${ }^{79}$ Poisson regression models were fitted to the data, as the number of sick leaves is a form of count data and as these models permit individual follow up times to be taken into account. Use of the Poisson model implies that the betweenemployee variance in the rates of sick leave is equal to the expected rate of sick leave. In this study, the dispersion in medically certified sick leaves did not significantly deviate from the assumptions for Poisson models.

We studied the associations of worktime control with self rated health and psychological distress by means of logistic regression and the associations with sickness absence by means of hierarchical Poisson regression models. Adjustments were made for demographics (age, educational level, marital status, and existence of dependent children), measures of health risk behaviour (smoking, alcohol consumption, body mass index, and sedentary life style), and baseline sickness absence. We then studied the associations with health of worktime control, job control and job demands both separately and in the same models, adjusted for demographics and health risk behaviour.

Worktime control, job control and job demands were divided into quartiles and treated as categorical variables. The results of regression analyses were expressed by odds ratios for logistic models and rate ratios for Poisson models, including their $95 \%$ confidence intervals. All analyses were performed separately for men and women. We used the SPSS statistical program ${ }^{43}$ and the GENMOD procedure of the SAS program package ${ }^{44}$ for the analyses.

\section{RESULTS}

\section{Worktime control and other predictors of health}

There was no difference in the level of worktime control between men and women (mean ratings 2.77 (SD 0.89) and 2.78 (SD 0.86) for men and women, respectively). In both genders, worktime control was linearly associated with job control (table 1). In men, poor worktime control was associated with low education and high job demands. In women, poor worktime control was related to high education, the existence of dependent children and low job demands.

\section{Associations between other predictors and health}

Poor health was associated with old age, low education, smoking, obesity, and sedentariness in both genders, and with no dependent children in women (table 2). Psychological distress was associated with sedentariness in both genders, with old age in men and with no partnership in women. Increased rates of sickness absence were predicted by low education, smoking, obesity, and sedentariness in both genders. In addition, men with no dependent children and women of old age had an increased risk of sickness absence. 
Table 2 Associations of demographics and measures of health behaviour with poor health, psychological distress, and medically certified sickness absences adjusted for age

\begin{tabular}{|c|c|c|c|c|c|c|}
\hline & \multicolumn{2}{|l|}{ Self rated poor health } & \multicolumn{2}{|l|}{ Psychological distress } & \multicolumn{2}{|l|}{ Sickness absence } \\
\hline & Men OR $(95 \% \mathrm{Cl})^{*}$ & $\begin{array}{l}\text { Women OR }(95 \% \\
\text { Cl)* }\end{array}$ & Men OR $(95 \% \mathrm{Cl})^{*}$ & $\begin{array}{l}\text { Women OR }(95 \% \\
\text { Cl)* }\end{array}$ & Men RR $(95 \% \mathrm{Cl}) \dagger$ & $\begin{array}{l}\text { Women RR (95\% } \\
\text { CI) } \dagger\end{array}$ \\
\hline \multicolumn{7}{|l|}{ Age group (y) } \\
\hline $18-39$ & 1.00 & 1.00 & 1.00 & 1.00 & 1.00 & 1.00 \\
\hline $40-49$ & 2.39 (1.72 to 3.31$)$ & 1.75 (1.48 to 2.07$)$ & 1.79 (1.28 to 2.51$)$ & $0.84(0.72$ to 0.99$)$ & 0.99 (0.87 to 1.12 ) & 1.03 (0.97 to 1.09$)$ \\
\hline$\geqslant 50$ & 3.80 (2.76 to 5.23$)$ & 3.59 (3.03 to 4.24$)$ & $1.56(1.11$ to 2.18$)$ & $1.07(0.91$ to 1.26$)$ & 0.99 (0.88 to 1.13$)$ & 1.15 (1.08 to 1.22$)$ \\
\hline \multicolumn{7}{|l|}{ Level of education } \\
\hline University & 1.00 & 1.00 & 1.00 & 1.00 & 1.00 & 1.00 \\
\hline College & 1.66 (1.19 to 2.30$)$ & 1.13 (0.94 to 1.37$)$ & 1.12 (0.81 to 1.54$)$ & 0.83 (0.69 to 0.99$)$ & 1.70 (1.42 to 2.02 ) & 1.57 (1.45 to 1.70$)$ \\
\hline Vocational & 2.18 (1.55 to 3.05$)$ & $1.49(1.22$ to 1.81$)$ & $0.82(0.58$ to 1.17$)$ & $0.67(0.55$ to 0.81$)$ & 3.01 (2.56 to 3.54$)$ & $2.02(1.86$ to 2.19$)$ \\
\hline None & 3.14 (2.27 to 4.34$)$ & $1.90(1.57$ to 2.30$)$ & 0.84 (0.59 to 1.19$)$ & $0.74(0.61$ to 0.90$)$ & 3.57 (3.05 to 4.18$)$ & 2.42 (2.24 to 2.62$)$ \\
\hline \multicolumn{7}{|c|}{ Married or cohabiting } \\
\hline Yes & 1.00 & 1.00 & 1.00 & 1.00 & 1.00 & 1.00 \\
\hline No & 1.31 (0.97 to 1.77 ) & 1.03 (0.89 to 1.19 ) & 1.35 (0.98 to 1.86$)$ & 1.22 (1.04 to 1.41$)$ & 1.07 (0.94 to 1.22 ) & $1.04(0.99$ to 1.10$)$ \\
\hline \multicolumn{7}{|c|}{ Dependent children } \\
\hline Yes & 1.00 & 1.00 & 1.00 & 1.00 & 1.00 & 1.00 \\
\hline No & $1.23(0.98$ to 1.55$)$ & 1.31 (1.15 to 1.49$)$ & $1.13(0.88$ to 1.45$)$ & $1.06(0.92$ to 1.21$)$ & $1.32(1.20$ to 1.46$)$ & $1.04(0.99$ to 1.10$)$ \\
\hline \multicolumn{7}{|l|}{ Smoking } \\
\hline Never smoker & 1.00 & 1.00 & 1.00 & 1.00 & 1.00 & 1.00 \\
\hline Ex smoker & $1.21(0.92$ to 1.59$)$ & $1.23(1.07$ to 1.41$)$ & $1.10(0.82$ to 1.47$)$ & $1.11(0.96$ to 1.28$)$ & 1.13 (1.00 to 1.27$)$ & $1.18(1.12$ to 1.24$)$ \\
\hline Current smoker & 1.55 (1.13 to 2.12$)$ & $1.60(1.34$ to 1.90$)$ & $1.16(0.82$ to 1.63$)$ & $1.10(0.92$ to 1.32$)$ & 1.61 (1.41 to 1.83$)$ & $1.44(1.36$ to 1.54$)$ \\
\hline \multicolumn{7}{|c|}{ Alcohol consumption } \\
\hline $0-210 \mathrm{~g} /$ week & 1.00 & 1.00 & 1.00 & 1.00 & 1.00 & 1.00 \\
\hline $\begin{array}{l}>210 \mathrm{~g} / \text { week } \\
\text { nas }\end{array}$ & $1.23(0.94$ to 1.61$)$ & $0.90(0.69$ to 1.19$)$ & 1.19 (0.89 to 1.59$)$ & 1.29 (0.99 to 1.69$)$ & 1.08 (0.97 to 1.21$)$ & 0.92 (0.82 to 1.02$)$ \\
\hline $\begin{array}{l}\text { Body mass index } \\
<25\end{array}$ & 1.00 & 1.00 & 1.00 & 1.00 & 1.00 & Body mass index \\
\hline $25-30$ & 1.49 (1.16 to 1.90$)$ & 1.75 (1.52 to 2.01$)$ & 0.94 (0.72 to 1.22$)$ & $0.99(0.85$ to 1.15$)$ & 1.27 (1.14 to 1.41$)$ & $1.39(1.31$ to 1.46$)$ \\
\hline$>30$ & $3.97(2.73$ to 5.78$)$ & 3.01 (2.48 to 3.66$)$ & $1.34(0.90$ to 1.98$)$ & 1.21 (0.98 to 1.49$)$ & 1.79 (1.55 to 2.07$)$ & 1.75 (1.64 to 1.87$)$ \\
\hline \multicolumn{7}{|c|}{ ק } \\
\hline No & 1.00 & 1.00 & 1.00 & 1.00 & 1.00 & 1.00 \\
\hline Yes & 3.39 (2.52 to 4.56$)$ & 2.19 (1.85 to 2.58$)$ & 1.93 (1.43 to 2.62 ) & 1.38 (1.17 to 1.64$)$ & 1.48 (1.32 to 1.66$)$ & 1.18 (1.11 to 1.25$)$ \\
\hline
\end{tabular}

\section{Worktime control and health}

In women, level of worktime control was consistently associated with subjective health. Odds ratios for poor health and psychological distress were twice as high among those in the lowest quartile of worktime control than those in the highest (table 3). In men, worktime control did not associate with poor health or psychological distress in the adjusted models.
In both men and women, employees in the two lowest quartiles of worktime control had a 1.2 times higher rate of medically certified sickness absences than those in the highest quartile, after adjustment for age, educational level, family characteristics, and traditional health risk behaviour. The association between worktime control and forthcoming sickness absence remained significant in women even after the adjustment for prior sickness absence.

Table 3 Odds ratios (95\% confidence intervals) of poor health and psychological distress and rate ratios $(95 \%$ confidence intervals) of sickness absences by quartiles of worktime control

\begin{tabular}{|c|c|c|c|c|c|c|}
\hline \multirow{2}{*}{$\begin{array}{l}\text { Quartiles of } \\
\text { worktime control }\end{array}$} & \multicolumn{2}{|l|}{ Self rated poor health } & \multicolumn{2}{|l|}{ Psychological distress } & \multicolumn{2}{|l|}{ Sickness absence } \\
\hline & Men & Women & Men & Women & Men & Women \\
\hline \multicolumn{7}{|c|}{ Model 1 adjusted for age } \\
\hline 4 (high) & 1.00 & 1.00 & 1.00 & 1.00 & 1.00 & 1.00 \\
\hline 3 & $1.53(1.10$ to 2.13$)$ & 1.30 (1.08 to 1.57$)$ & 0.90 (0.63 to 1.28$)$ & 1.38 (1.14 to 1.67$)$ & 1.28 (1.10 to 1.49$)$ & $1.13(1.06$ to 1.21$)$ \\
\hline 2 & 1.81 (1.32 to 2.49 ) & 1.61 (1.34 to 1.93 ) & 1.15 (0.82 to 1.60$)$ & $1.50(1.24$ to 1.81$)$ & 1.69 (1.47 to 1.94$)$ & 1.30 (1.21 to 1.38$)$ \\
\hline 1 (low) & 1.07 (1.05 to 1.08$)$ & 1.88 (1.56 to 2.26$)$ & $1.04(0.74$ to 1.47$)$ & 1.85 (1.53 to 2.25$)$ & $1.48(1.28$ to 1.71$)$ & 1.15 (1.07 to 1.23$)$ \\
\hline \multicolumn{7}{|c|}{ Model 2 adjusted for age and other demographics* } \\
\hline 4 (high) & 1.00 & 1.00 & 1.00 & 1.00 & 1.00 & 1.00 \\
\hline 3 & $1.24(0.80$ to 1.75$)$ & $1.24(1.02$ to 1.50$)$ & 0.95 (0.65 to 1.37$)$ & $1.43(1.17$ to 1.74$)$ & $1.01(0.87$ to 1.18$)$ & $1.06(0.99$ to 1.14$)$ \\
\hline 2 & 1.44 (1.03 to 2.02$)$ & $1.54(1.27$ to 1.85$)$ & $1.27(0.89$ to 1.81$)$ & 1.55 (1.27 to 1.89$)$ & $1.25(1.08$ to 1.45$)$ & 1.21 (1.14 to 1.30$)$ \\
\hline 1 (low) & 1.37 (0.97 to 1.93$)$ & $2.01(1.65$ to 2.44$)$ & $1.15(0.80$ to 1.65$)$ & 1.91 (1.55 to 2.34$)$ & 1.17 (1.01 to 1.37$)$ & $1.21(1.12$ to 1.30$)$ \\
\hline \multicolumn{7}{|c|}{ Model 3 adjusted for age, other demographics and health behaviour $†$} \\
\hline 4 (high) & 1.00 & 1.00 & 1.00 & 1.00 & 1.00 & 1.00 \\
\hline 3 & $1.23(0.85$ to 1.76$)$ & $1.28(1.04$ to 1.56$)$ & $0.94(0.65$ to 1.38$)$ & $1.49(1.22$ to 1.83$)$ & $1.02(0.87$ to 1.19$)$ & $1.08(1.01$ to 1.16$)$ \\
\hline 2 & 1.41 (0.99 to 2.01$)$ & $1.59(1.31$ to 1.94$)$ & $1.22(0.85$ to 1.75$)$ & $1.57(1.28$ to 1.92$)$ & $1.23(1.06$ to 1.43$)$ & $1.23(1.14$ to 1.31$)$ \\
\hline 1 (low) & $1.36(0.95$ to 1.97$)$ & 2.21 (1.80 to 2.72$)$ & 1.15 (0.79 to 1.67$)$ & 1.99 (1.61 to 2.45$)$ & $1.20(1.03$ to 1.41$)$ & $1.22(1.13$ to 1.32$)$ \\
\hline \multicolumn{7}{|c|}{ Model 4 adjusted for age, other demographics, health behaviour and baseline health $\ddagger$} \\
\hline 4 (high) & 1.00 & 1.00 & 1.00 & 1.00 & 1.00 & 1.00 \\
\hline 3 & $1.25(0.86$ to 1.80$)$ & 1.28 (1.04 to 1.57$)$ & $0.96(0.66$ to 1.42$)$ & 1.50 (1.23 to 1.84$)$ & $1.05(0.89$ to 1.23$)$ & $1.08(1.01$ to 1.16$)$ \\
\hline 2 & 1.45 (1.01 to 2.07$)$ & 1.56 (1.28 to 1.91$)$ & $1.24(0.86$ to 1.78$)$ & 1.54 (1.26 to 1.89$)$ & $1.15(0.99$ to 1.34$)$ & $1.18(1.10$ to 1.26$)$ \\
\hline 1 (low) & $1.32(0.92$ to 1.91$)$ & 2.20 (1.78 to 2.72$)$ & $1.14(0.79$ to 1.66$)$ & $1.96(1.59$ to 2.42$)$ & $1.10(0.94$ to 1.28$)$ & $1.19(1.10$ to 1.28$)$ \\
\hline
\end{tabular}

*Educational level, marital status, existence of dependent children; †smoking, alcohol consumption, body mass index, sedentariness; $\ddagger$ Baseline sickness absence. 
Table 4 Associations of work characteristics with health

\begin{tabular}{|c|c|c|c|c|}
\hline \multirow[b]{2}{*}{ Work characteristics } & \multicolumn{2}{|c|}{ Model 1: work characteristics analysed separately $\dagger$} & \multicolumn{2}{|c|}{ Model 2: work characteristics analysed together $\ddagger$} \\
\hline & Men & Women & Men & Women \\
\hline \multicolumn{5}{|l|}{ Self rated poor health§ } \\
\hline \multicolumn{5}{|l|}{ Worktime control } \\
\hline 4 (high)* & 1.00 & 1.00 & 1.00 & 1.00 \\
\hline 3 & $1.23(0.85$ to 1.76$)$ & 1.28 (1.04 to 1.56$)$ & $1.09(0.76$ to 1.58$)$ & $1.18(0.96$ to 1.44$)$ \\
\hline 2 & 1.41 (0.99 to 2.01$)$ & $1.59(1.31$ to 1.94$)$ & $1.39(0.97$ to 1.99$)$ & $1.42(1.16$ to 1.73$)$ \\
\hline 1 (low) & 1.36 (0.95 to 1.97$)$ & $2.21(1.80$ to 2.72$)$ & $1.22(0.84$ to 1.78$)$ & 1.84 (1.49 to 2.28 ) \\
\hline \multicolumn{5}{|l|}{ Job control } \\
\hline 4 (high) & 1.00 & 1.00 & 1.00 & 1.00 \\
\hline 3 & 1.55 (1.07 to 2.26$)$ & 1.27 (1.03 to 1.57$)$ & 1.63 (1.11 to 2.38$)$ & 1.28 (1.03 to 1.59$)$ \\
\hline 2 & 1.60 (1.11 to 2.32$)$ & 1.55 (1.26 to 1.90$)$ & $1.74(1.19$ to 2.54$)$ & 1.55 (1.26 to 1.92$)$ \\
\hline 1 (low) & 2.00 (1.34 to 2.97$)$ & 1.96 (1.58 to 2.44$)$ & $2.11(1.40$ to 3.20$)$ & 1.86 (1.49 to 2.33 ) \\
\hline \multicolumn{5}{|l|}{ Job demands } \\
\hline 1 (low) & 1.00 & 1.00 & 1.00 & 1.00 \\
\hline 2 & $1.14(0.79$ to 1.65$)$ & 1.64 (1.34 to 2.01$)$ & $1.14(0.78$ to 1.65$)$ & $1.57(1.28$ to 1.93$)$ \\
\hline 3 & 1.49 (1.05 to 2.09$)$ & 2.00 (1.65 to 2.42$)$ & $1.56(1.10$ to 2.20$)$ & 1.93 (1.59 to 2.34 ) \\
\hline 4 (high) & 1.77 (1.24 to 2.53$)$ & 2.15 (1.76 to 2.62 ) & 1.95 (1.36 to 2.81 ) & 2.07 (1.69 to 2.54$)$ \\
\hline \multicolumn{5}{|c|}{$\begin{array}{l}4 \text { (high) } \\
\text { Psychological distress } \S\end{array}$} \\
\hline \multicolumn{5}{|l|}{ Worktime control } \\
\hline 4 (high) & 1.00 & 1.00 & 1.00 & 1.00 \\
\hline 3 & 0.94 (0.65 to 1.38$)$ & 1.49 (1.22 to 1.83$)$ & 1.83 (0.56 to 1.23 ) & 1.40 (1.13 to 1.72$)$ \\
\hline 2 & $1.22(0.85$ to 1.75$)$ & $1.57(1.28$ to 1.92$)$ & $1.18(0.81$ to 1.71$)$ & 1.38 (1.12 to 1.70$)$ \\
\hline 1 (low) & 1.15 (0.79 to 1.67$)$ & $1.99(1.61$ to 2.45$)$ & $1.00(0.67$ to 1.48$)$ & 1.61 (1.29 to 2.00$)$ \\
\hline \multicolumn{5}{|l|}{ Job control } \\
\hline 4 (high) & 1.00 & 1.00 & 1.00 & 1.00 \\
\hline 3 & 1.24 (0.84 to 1.83$)$ & 1.30 (1.05 to 1.60$)$ & 1.48 (0.99 to 2.22$)$ & 1.31 (1.05 to 1.63 ) \\
\hline 2 & 1.53 (1.04 to 2.24$)$ & 1.63 (1.33 to 2.01$)$ & 1.99 (1.33 to 2.99 ) & 1.69 (1.37 to 2.09 ) \\
\hline 1 (low) & $2.12(1.41$ to 3.21$)$ & 2.01 (1.61 to 2.50$)$ & $2.79(1.79$ to 4.34$)$ & 2.05 (1.63 to 2.58 ) \\
\hline \multicolumn{5}{|l|}{ Job demands } \\
\hline 1 (low) & 1.00 & 1.00 & 1.00 & 1.00 \\
\hline 2 & 1.23 (0.80 to 1.89 ) & 1.63 (1.30 to 2.05 ) & 1.23 (0.79 to 1.91 ) & 1.58 (1.25 to 1.98 ) \\
\hline 3 & 1.84 (1.24 to 2.71$)$ & $2.70(2.19$ to 3.33$)$ & 1.95 (1.31 to 2.90$)$ & $2.69(2.18$ to 3.31$)$ \\
\hline 4 (high) & $3.62(2.47$ to 5.31$)$ & $4.20(3.40$ to 5.19$)$ & 4.27 (2.88 to 6.33 ) & 4.20 (3.39 to 5.21$)$ \\
\hline \multicolumn{5}{|l|}{ Sickness absencef } \\
\hline \multicolumn{5}{|l|}{ Worktime control } \\
\hline 4 (high) & 1.00 & 1.00 & 1.00 & 1.00 \\
\hline 3 & 1.02 (0.87 to 1.19 ) & 1.08 (1.01 to 1.16$)$ & 0.98 (0.84 to 1.15$)$ & 1.06 (0.99 to 1.14$)$ \\
\hline 2 & 1.23 (1.06 to 1.43 ) & $1.23(1.14$ to 1.31$)$ & $1.19(1.02$ to 1.38$)$ & $1.18(1.10$ to 1.26$)$ \\
\hline 1 (low) & 1.20 (1.03 to 1.41$)$ & $1.22(1.13$ to 1.32$)$ & $1.13(0.96$ to 1.33$)$ & 1.15 (1.06 to 1.24$)$ \\
\hline \multicolumn{5}{|l|}{ Job control } \\
\hline 4 (high) & 1.00 & 1.00 & 1.00 & 1.00 \\
\hline 3 & $0.96(0.82$ to 1.14$)$ & 1.11 (1.02 to 1.20$)$ & 0.98 (0.83 to 1.16$)$ & $1.16(1.02$ to 1.20$)$ \\
\hline 2 & 1.07 (0.92 to 1.25 ) & 1.23 (1.14 to 1.33 ) & $1.10(0.93$ to 1.29$)$ & 1.23 (1.14 to 1.33 ) \\
\hline 1 (low) & 1.28 (1.10 to 1.50$)$ & $1.32(1.22$ to 1.43$)$ & $1.29(1.09$ to 1.52$)$ & 1.28 (1.18 to 1.39 ) \\
\hline \multicolumn{5}{|l|}{ Job demands } \\
\hline 1 (low) & 1.00 & 1.00 & 1.00 & 1.00 \\
\hline 2 & 0.86 (0.75 to 1.00$)$ & 1.16 (1.08 to 1.24$)$ & 0.85 (0.73 to 0.98$)$ & 1.14 (1.06 to 1.22 ) \\
\hline 3 & $1.03(0.90$ to 1.18$)$ & $1.12(1.05$ to 1.20$)$ & $1.06(0.92$ to 1.21$)$ & 1.11 (1.04 to 1.19 ) \\
\hline 4 (high) & $1.10(0.96$ to 1.27$)$ & $1.26(1.17$ to 1.35$)$ & $1.14(0.99$ to 1.32$)$ & 1.24 (1.15 to 1.33 ) \\
\hline
\end{tabular}

As shown in table 4, in women the strength of the association between worktime control and all indicators of health was similar in magnitude to that between job control and health. An effect of worktime control was still evident after adjustment for job control and job demands. In both men and women, there was an association between level of worktime control and sickness absence. However, after adjustment for other work characteristics the association was significant only in women.

To study whether the differences in the results between men and women were accounted for by the differences in distributions of occupations, we analysed the results adjusting for occupational status instead of educational level. Findings were similar in all cases.

\section{Subgroup analysis in teachers}

As a final step, we analysed the association between worktime control and health within a single occupation, teachers, the largest occupational group of our sample comprising both men $(n=297)$ and women $(n=916)$. Compared with the high- est quartile of worktime control, the odds ratios of the lowest quartile for poor health were 3.21 ( 1.54 to 6.69) among female teachers and 1.71 (0.62 to 4.72$)$ among male teachers (adjusted for age, educational level, marital status, existence of dependent children, smoking, alcohol consumption, body mass index, and sedentary life style). The corresponding figures for psychological distress were 2.45 ( 1.33 to 4.54 ) and 1.14 (0.44 to 2.92) in female and male teachers, respectively. Women in the lowest quartile of worktime control had a 1.23 (0.95 to 1.59) times higher rate of medically certified sickness absence than those in the highest quartile. The corresponding rate ratio was 0.93 (0.58 to 1.51$)$ in men. Thus, the results within a single occupational group were well in line with those found in the total sample (table 3, model 3).

\section{DISCUSSION}

We found that control over working times in women was associated with aspects of health such as self rated health status, psychological distress, and medically certified sickness 
absence. Furthermore, as poor worktime control predicted sickness absence even after controlling for baseline sick leaves and other dimensions of control, our results indicate that poor worktime control is an independent health risk in women.

Previous studies have suggested an increased risk of cardiovascular morbidity in occupations characterised by poor worktime control, in both men and women. ${ }^{27}{ }^{28}$ However, in these studies potential confounding factors were not controlled for as extensively as in the study reported here.

\section{Worktime control as a control dimension}

Sargent and Terry ${ }^{45}$ have suggested a distinction between the task relevant and peripheral dimensions of control, the former having been the main focus in prior research. ${ }^{1-14}{ }^{18-24}$ In this classification, worktime control appears as peripheral. Although in men the health effects of task-relevant aspects such as skill discretion and decision authority were stronger than those related to worktime control, our results for female employees support the importance of extending the research beyond the task relevant dimension of control at work. ${ }^{15}{ }^{17}$

\section{Possible explanations for the gender specific results}

Explanations for the differences between men and women in the health effects of worktime control may relate to at least two categories of factors: total workload and work characteristics.

Prior research suggests that the differences in workloads between genders are great at home but less obvious at work within the same occupational groups. Thus, in the case of similar loads at work between men and women, women face a larger total workload because of their major share of home responsibilities. ${ }^{46}$ Studies on top level managers, for example, showed that the levels of stress hormone excretions ${ }^{47} 48$ and blood pressure ${ }^{47}$ did not differ between men and women during the workday. However, in the evening these levels decreased in men but increased in women, reflecting the gender differences in unpaid work.

Control over working times contributes to employees' opportunities to successfully manage the work/non-work interface and to integrate working life with private life. Thus, high worktime control could provide better opportunities to control not only the load of paid work but also the total workload. As housekeeping responsibilities concern women more than men, the important role of worktime control among aspects of control, especially in women, is to be expected. ${ }^{17}$

It is also possible that the gender specific health effects of worktime control stem from differences in work characteristics between men and women. To examine this, we studied the largest two gender occupation in our sample, the teachers. Compared with the total sample, variation in work characteristics between men and women was low within this occupational group. Despite this, the gender specific results on worktime control and health were replicated, and in magnitudes similar to the total sample.

Findings on teachers suggest that differences in formal work characteristics do not explain the observed gender differences in the effects of worktime control on health. However, these findings do not rule out explanations related to differences in actual work characteristics or perceptions on work. We found differences in perceived work characteristics between men and women. Although high educational level is usually associated with high job control and position in the organisational hierarchy, results on control over worktime followed this pattern only in men. In fact, perceived worktime control was lowest in women with a university level education. Corresponding results have been derived from a study of the British Birth Cohort $1958^{49}$ in which flexibility of break times produced a socioeconomic gradient in men, but not in women.

\section{Key points}

- Worktime control is associated with health in women.

- This association is independent of job control.

- Dissimilaties in the distribution of occupations are not a probable explanation for the gender difference.

\section{Methodological considerations}

We used three measures of ill health, two related to self reports of subjective experiences and one to archival data of functional disability. Reflecting a high robustness of the main findings, the results were replicable across all these measures both in the total sample and its subgroup of teachers. Self rated health and GHQ are well established health outcomes. ${ }^{33} 34{ }^{37}$ Sickness absences also serve as a measure of health in the working population when health is understood as a mixture of social, psychological, and physiological functioning. ${ }^{50}{ }^{51}$ Recorded sickness absence data have several advantages: they cover information on the health problems during every working day of the total study period, and the quality of the data in terms of coverage, accuracy, and consistency over time is superior to that attainable via self reports.

It could be argued that controlling for health behaviour and other work characteristics is overadjusting, as these factors may reflect different aspects of a single process, and as adverse work characteristics tend to accumulate in particular individuals. Our findings in the fully adjusted models therefore represent conservative estimates of the independent effects of worktime control.

Comparison of the magnitudes of the effects shows that worktime control was more strongly associated with self reports of health than with register based absences. It is possible that common method variance is partially responsible for the higher effect size. One may ask whether the observed effect sizes are large enough to be significant in working life. We argue that this is the case because considerable costs can be expected as half of the female workforce with poorer than median level worktime control had a $20 \%$ excess of medically certified sickness absence. Furthermore, worktime control represents a potentially reversible factor of ill health.

\section{CONCLUSION}

The modernisation of working times is a major issue in societies throughout Europe. The main trends can be characterised as differentiation and individualisation of working times, as the institutional frame has become flexible and local. Flexibility in working times is increasingly common. ${ }^{3152}$ Although such flexibility has been introduced to meet many employers' viewpoints, it may also provide opportunities for a better fit of private needs with occupational demands among employees.

Our findings suggest that a high level of control over working times buffers against health problems in women but not necessarily in men. Worktime control may help in integrating working and private lives. The greater significance of worktime control in female employees may relate to gender differences in roles at home rather than to gender related occupational segregation.

\section{ACKNOWLEDGEMENTS}

Funding: this study was supported by the Finnish Work Environment Foundation (project no 96238), the Academy of Finland (project no 44968), the Finnish Occupational Safety and Health Administration, The Finnish Local Government Pensions Institution and the participating towns.

Conflicts of interest: none.

Authors' affiliations

L Ala-Mursula, Development and Service Centre of Occupational Health, City of Oulu, and Department of Public Health Science and 
General Practice, University of Oulu, Finland

J Vahtera, J Pentti, Finnish Institute of Occupational Health, Turku, Finland

M Kivimäki, Department of Psychology, Division of Applied Psychology, University of Helsinki, Finland

M V Kevin, Department of Public Health, University of Turku, Finland

\section{REFERENCES}

1 Karasek R, Baker D, Marxer F, et al. Job decision latitude, job demands, and cardiovascular disease: a prospective study of Swedish men. Am J Public Health 1981;71:694-705.

2 Marmot MG, Bosma H, Hemingway H, et al. Contribution of job control and other risk factors to social variations in coronary heart disease incidence. Lancet 1997:350:235-9.

3 Bobak M, Hertzman C, Skodova Z, et al. Association between psychosocial factors at work and nonfatal myocardial infarction in a population-based case-control study in Czech men. Epidemiology 1998;9:43-7.

4 Bosma H, Peter R, Siegrist J, et al. Two alternative job stress models and the risk of coronary heart disease. Am J Public Health 1998;88:68-74.

5 Theorell T, Tsutsumi A, Hallquist J, et al. Decision latitude, job strain, and myocardial infarction: A study of working men in Stockholm. Am J Public Health 1998:88:382-8.

6 Johnson JV, Stewart W, Hall EM, et al. Long-term psychosocial work environment and cardiovascular mortality among Swedish men. Am J Public Health 1996;86,324-31

7 North F, Syme SL, Feeney A, et al. Explaining socioeconomic differences in sickness absence: the Whitehall II study. BMU 1993;306:361-6.

8 Melamed S, Ben-Avi I, Luz J, et al. Objective and subjective work monotony: effects on job satisfaction, psychological distress, and absenteeism in blue-collar workers. J Appl Psychol 1995;80:29-42.

9 North F, Syme SL, Feeney A, et al. Psychosocial work environment and sickness absence among British civil servants: The Whitehall II study. Am J Public Health 1996:86:332-40.

10 Kivimäki M, Vahtera J, Thomson J, et al. Psychosocial factors predicting employee sickness absence during economic decline. J Appl Psychol 1997;82:858-72.

11 Lerner DJ, Levine S, Malspeis S, et al. Job strain and health-related quality of life in a national sample. Am J Public Health 1994;84: 1580-5.

12 Amick BC III, Kawachi I, Coakley EH, et al. Relationship of job strain and iso-strain to health status in a cohort of women in the United States. Scand J Work Environ Health 1998;24:54-61.

13 Stansfeld SA, Bosma $\mathrm{H}$, Hemingway $\mathrm{H}$, et al. Psychosocial work characteristics and social support as predictors of SF-36 health functioning: The Whitehall II Study. Psychosom Med 1998;60:247-55.

14 Cheng Y, Kawachi I, Coakley EH, et al. Association between psychosocial work characteristics and health functioning in American women: prospective study. BM 2000;320:1432-6.

15 Ganster DC. Improving measures of worker control in occupationa stress research. In: Hurrell JJ Jr, Murphy LR, Sauter SL, et al, eds. Occupational stress: issues and developments in research. Philadelphia, PA: Taylor and Francis, 1988:88-99.

16 Aronsson G. Dimensions of control as related to work organization stress, and health. Int J Health Serv 1989;19:459-68.

17 Frese M. Theoretical models of control and health. In: Sauter SL, Hurrell JA, Cooper CL, eds. Job control and worker health. Chichester: Wiley, 1989:107-28.

18 Frankenhaeuser M. Coping with stress at work. Int J Health Serv $1981 ; 11: 491-510$

19 Alfredsson L, Karasek R, Theorell T. Myocardial infarction risk and psychosocial work environment: an analysis of the male Swedish working force. Soc Sci Med 1982;16:463-46.

20 Kivimäki $M$, Vahtera J, Pentti J. Factors underlying the effect of organizational downsizing on health of employees: longitudinal cohort study. BM 2000;320:971-5.

21 Vahtera J, Kivimäki M, Pentti J et al. Effect of change in the psychosocial work environment on sickness absence: a seven year follow up of initially healthy employees. J Epidemiol Community Health 2000;54:484-93.

22 Spector PE. Perceived control by employees: a meta-analysis of studies concerning autonomy and participation at work. Human Relations 1986;39:1005-16.

23 Steptoe A, Fieldman G, Evans O, et al. Control over work pace, job strain and cardiovascular responses in middle-aged men. J Hypertens 1993;11:751-9.

24 Jackson SE. Participation in decision making as a strategy for reducing job-related strain. J Appl Psychol 1983;68:3-19.
25 Johansson $\mathbf{G}$. Job demands and stress reactions in repetitive and uneventful monotony at work. In: Johnson JV, Johansson G, eds. The psychosocial work environment: work organization, democratization and health. Amityville, NY: Baywood Publishing, 1991:61-72.

26 Baltes B, Briggs TE, Huff JW, et al. Flexible and compressed workweek schedules: a meta-analysis of their effects on work-related criteria. J Appl Psychol 1999;84:496-513

27 Alfredsson L, Spetz C-L, Theorell T. Type of occupation and near-future hospitalization for myocardial infarction and some other diagnoses. Int J Epidemiol 1985;14:378-88.

28 Hammar N, Alfredsson L, Theorell T. Job characteristics and the incidence of myocardial infarction. Int J Epidemiol 1994;23:277-84.

29 Vahtera J, Kivimäki M, Pentti J. Effect of organizational downsizing on health of employees. Lancet 1997;350:1124-8.

30 Lehto A-M. Quality of working life and equity. Helsinki: Statistics Finland, 1991.

31 Knauth P. Innovative worktime arrangements. Scand J Work Environ Health 1998;24 (suppl 3):13-17.

32 Ganster DC. Worker control and well-being: a review of research in the workplace. In: Sauter SL, Hurrell JA, Cooper CL, eds. Job control and worker health. Chichester: Wiley, 1989:3-23.

33 Idler EL, Angel RJ. Self-rated health and mortality in the NHANES-I epidemiologic follow-up study. Am J Public Health 1990;80:446-52.

34 Kaplan GA, Goldberg DE, Everson SA, et al. Perceived health status and morbidity and mortality: evidence from the Kuopio ischemic heart disease risk factor study. Int J Epidemiol 1996;25:259-65.

35 Miilunpalo S, Vuori I, Oja P, et al. Self-rated health status as a health measure: the predictive value of self-reported health status on the use of physician services and on mortality in the working-age population. J Clin Epidemiol 1997;50:517-28.

36 Goldberg D, Williams P. A user's guide to the General Health Questionnaire. Berkshire, UK: NFER-Nelson, 1988.

37 Goldberg DP, Gater R, Sartorius N, et al. The validity of the two versions of the GHQ in the WHO study of mental illness in general health care. Psychol Med 1997;27:191-7.

38 Karasek RA. Job Content Questionnaire and user's guide. Revision 1.1. Lowell, MA: University of Massachusetts, Department of Work Environment, 1985

39 Statistics Finland. Classification of occupations, handbook no 14. Helsinki: Statistics Finland, 1997

40 Kaprio J, Koskenvuo M, Langinvainio $\mathrm{H}$, et al. Genetic influences on use and abuse of alcohol: a study of 5638 adult Finnish twin brothers. Alcohol Clin Exp Res 1987;11:349-56.

41 Rimm EB, Williams P, Fosher K, et al. Moderate alcohol intake and lower risk of coronary heart disease: meta-analysis of effects on lipids and haemostatic factors. BM 1999;319:1523-8.

42 Kujala UM, Kaprio J, Sarna S, et al. Relationship of leisure-time physical activity and mortality. The Finnish twin cohort. JAMA 1998:279:440-4.

43 SPSS Inc. SPSS advanced models 9.0. Chicago, IL: SPSS, 1999.

44 SAS Technical Report P-243, SAS/STAT Software: The Genmod procedure, release 6.09. Cary, N.C: SAS Institute, 1993

45 Sargent LS, Terry DJ. The effects of work control and job demands on employee adjustment and work performance. J Occup Organ Psychol 1998;71:219-36

46 Lundberg U, Mårdberg B, Frankenhaeuser M. The total workload of male and female white collar workers as related to age, occupational level, and number of children. Scand J Psychol 1994;35:315-27.

47 Frankenhaeuser $\boldsymbol{M}$. The psychophysiology of sex differences as related to occupational status. In: Frankenhaeuser $M$, Lundberg $U$, Chesney $M$ eds: Women, work and health: stress and opportunities. New York: Plenum Press, 1991:39-61.

48 Lundberg U, Frankenhaeuser M. Stress and workload of men and women in high-ranking positions. J Occup Health Psychol $1999 \cdot 4: 142-51$.

49 Matthews S, Hertzman C, Ostry A, et al. Gender, work roles and psychosocial work characteristics as determinants of health. Soc Sci Med 1998;46:1417-24.

50 Marmot MG, Feeney A, Shipley M, et al. Sickness absence as a measure of health status and functioning: from the UK Whitehall II study. J Epidemiol Community Health 1995;49:124-30.

51 World Health Organisation. Health for All by the Year 2000 Copenhagen: World Health Organisation, Regional Office for Europe, 1986.

52 Julkunen R, Nätti J. The modernization of working times: flexibility and work sharing in Finland. Jyväskylä, Finland: SoPhi, University of Jyväskylä, 1999 